\title{
Media Violence and Childhood Depression
}

\author{
Tanjir Rashid Soron*, Gazi Farzana Sharmin Srabony and Chaman Afrooz Chowdhury \\ Tele-psychiatry Research and Innovation Network, Dhaka, Bangladesh
}

Though violence is an ancient phenomenon it emerged as an increasing problem in modern society due to more exposure to violence in television channels, internet, social networking sites, and mobile games and so on. Exposure to media violence is a significant risk of psychological well-being and development of the children. Their developing brain goes though the learning process and still at highest risk of making immature and improper decisions [1]. Among the various mental health problems depression is one of the major problems they encounter. However, its burden is frequently underestimated in the developing world due to lack of evidence from proper research and sociocultural stigma. About $2.8 \%$ children below the age 13 suffer from depression and the rate increased to $5.6 \%$ among the children between 13 to 18 year [2]. A number of bio-psychosocial factors interact together and lead to depression. Among the biological factors genetic influence and positive family history noteworthy, the other important factors are psychosocial factors (e.g. quality of attachment, relation between parents, family support, self-esteem and cognitions pattern) and several environmental factors (parental loss, divorce, physical/sexual abuse and illness or death of parents) [3].

In this era of gadgets and gear our family dynamic and parentchildren relation entered in a complex dynamics where mind machine interaction becomes a new domain of research. Electronic devices are exposing our minds to the different types of violence from the news room to play station. About $86 \%$ of the adolescent in Hong Kong use smart device daily [4] and the smart phone use by adolescent is increasing in an alarming rate in most of the countries. A study conducted about 20 year back that was cited by [5] The UNESCO Global Media Violence Study showed $93 \%$ of children who attend school spent more than $50 \%$ of their leisure time watching television and the rate has increased. Moreover, more than half of the program contained violence incidence.

Media violence is considered as visual portrayals of acts of physical aggression by one human or human-like character against another [6]. However, it also has a broader view with the span of time. A significant number of papers documented that exposure to media violence leads to aggressive behaviour in children [7-9]. The impact of media violence on the mood of the children is yet to reach get adequate attention due to lack of significant evidence to prove the causal relation between depression and media violence.

However, exposure to electronic media may be one of the factors that influence development of depression as it cut down their opportunity to acquire protective experiences from their family or peers which require active social, intellectual, or athletic engagement [10]. In addition, it distorts their sleep and optimal development of executive functioning and cognitive process. This distortion can lead to depression.

A number of studies indicate children's and adolescents' exposure to real-life violence, either as victims or witnesses, is associated with poor mental health outcomes including anxiety, depression, and posttraumatic stress disorder. Furthermore, children who played highviolence video games for more than 2 hours per day had significantly more depressive symptoms than those who playing low-violence video games for less than 2 hours per day [11]. However, others found no significant relation with video games and depression [12]. Television is another most common electronic device than has entered in the bed room of most of the children. Research showed children aged around 10 year who watched television more than 2 hours had low self-esteem in Hong Kong and China [13]. The scenario is also similar in the world of internet and social networking sites. Internet use raised the risk of depression [14] it correlates with online activity by younger people with low self-esteem [15] and loneliness [16].

Cyber bullying appears as a new threat for adolescent wellbeing. From a US national representative sample researchers found Cyber victims reported higher depression than bullies or bully-victims of offline [17].

Most of these studies conducted in developed countries, however, the evidence from the low and middle income countries are missing Facebook is affecting children and making them victim of violence in Bangladesh [18]. The social structure changing all over the world, the culture joint family is replaced by nuclear family and both parents are now working for a better and secure live.

Children and adolescent are suspected to be more vulnerable to media violence due to easy availability of smart devices with internet, satellite television and social media. Large scale international collaborative research is required to reach to the conclusion on intensity and extent of the media violence or childhood depression. This paper intended to draw the attention of the experts and policy maker to address the childhood depression particularly in the low and middle income countries so that they take necessary steps to protect our future generation.

\section{References}

1. Florea M (2013) Media violence and the cathartic effect. Soc Behav Sci 92 349-353.

2. Jane Costello E, Erkanli A, Angold A (2006) Is there an epidemic of child or adolescent depression? J Child Psychol Psychiatry Allied Discip 47: 12631271.

3. Kapornai K, Vetró A (2008) Depression in children. Curr Opin Psychiatry 21: 1-7.

4. Kwok SWH, Lee PH, Lee RLT (2017) Smart device use and perceived physical and psychosocial outcomes among Hong Kong adolescents. Int J Environ Res Public Health.

5. Browne KD, Hamilton-Giachritsis C (2005) The influence of violent media on children and adolescents: A public health approach. Lancet 365: 702-710.

*Corresponding author: Tanjir Rashid Soron, Tele-psychiatry Research and Innovation Network, Dhaka, Bangladesh, Tel: 880-1718827138; E-mail: tanjirsoron@yahoo.com.

Received: October 31, 2017; Accepted: November 27, 2017; Published: January 10, 2018

Citation: Soron TR, Srabony GFS, Chowdhury CA (2018) Media Violence and Childhood Depression. J Psychiatry 21: 439. doi:10.4172/2378-5756.1000439

Copyright: $\odot 2018$ Soron TR, et al. This is an open-access article distributed under the terms of the Creative Commons Attribution License, which permits unrestricted use, distribution, and reproduction in any medium, provided the original author and source are credited 
Citation: Soron TR, Srabony GFS, Chowdhury CA (2018) Media Violence and Childhood Depression. J Psychiatry 21: 439. doi:10.4172/23785756.1000439

Page 2 of 2

6. Huesmann LR (2007) The impact of electronic media violence: Scientific theory and research. J Adolesc Heal 41: 1-12.

7. Bushman BJ, Huesmann LR (2006) Short-term and long-term effects of violent media on aggression in children and adults. Arch Pediatr Adolesc Med 160: 348-352.

8. Cantor J (2003) Review of "Media violence and its effect on aggression: Assessing the scientific evidence." J Mass Commun Q 80: 468-470.

9. Murray JP (2008) Media violence: The effects are both real and strong. Am Behav Sci 51: 1212-1230.

10. Primack B, Swanier B, Georgiopoloulos A, Land S, Fine M (2009) Association between media use in adolescence and depression in young adulthood: a longitudinal study. Arch Gen Psychiatry 66: 181-188.

11. Tortolero SR, Peskin MF, Baumler ER, Cuccaro PM, Elliott MN, et al. (2014) Daily violent video game playing and depression in preadolescent youth. Cyberpsychology Behav Soc Netw 17: 609-615.

12. Valadez JJ, Ferguson CJ (2012) Just a game after all: Violent video game exposure and time spent playing effects on hostile feelings, depression, and visuospatial cognition. Comput Human Behav 28: 608-616.

13. Shiue I (2015) Duration of daily TV/screen watching with cardiovascular respiratory, mental and psychiatric health: Scottish Health Survey, 2012-2013. Int J Cardiol 186: 241-246.

14. Young KS, Rodgers RC (1998) The relationship between depression and internet addiction. CyberPsychology Behav 1: 25-28.

15. Caplan SE (2002) Problematic internet use and psychosocial well-being Development of a theory-based cognitive-behavioural measurement instrument. Comput Human Behav 18: 553-575.

16. Clayton RB, Osborne RE, Miller BK, Oberle CD (2013) Loneliness, anxiousness, and substance use as predictors of Facebook use. Comput Human Behav 29 687-693.

17. Wang J, Nansel TR, lannotti RJ (2011) Cyber and traditional bullying: Differential association with depression. J Adolesc Heal 48: 415-417.

18. Soron TR, Chowdhury CA (2016) Facebook, violence and safety of children in Bangladesh. J Psychiatry 19: 1-2 